\title{
O CONJUNTO ARQUITETÔNICO FÉRREO DE PRESIDENTE EPITÁCIO COMO UM PATRIMÔNIO CULTURAL LOCAL
}

\author{
Mayara Mota Cordeiro Souza, Fabrícia Dias da Cunha de Moraes Fernandes Borges \\ Universidade do Oeste Paulista - UNOESTE, Curso de Arquitetura e Urbanismo, Presidente Prudente - SP. E- \\ mail: mayaracordeiros@hotmail.com
}

\begin{abstract}
RESUMO
Os conjuntos arquitetônicos férreos, bem como as ferrovias de modo geral, possuem grandes relevâncias onde se inserem, devido serem marcos de um processo de desenvolvimento de muitas cidades brasileiras. Através de suas instalações é que em inúmeros municípios chegaram o desenvolvimento político, econômico e cultural, sendo assim consideradas patrimônio histórico e cultural local. Com isso, o presente artigo se estrutura com o objetivo apresentar um breve histórico do conjunto arquitetônico férreo da cidade de Presidente Epitácio, assim como sua devida importância para o município e o estado de conservação que hoje se encontra. As metodologias trabalhadas baseiam-se em pesquisas bibliográficas e documentais sobre a história da ferrovia no município de Presidente Epitácio-SP, bem como levantamentos in loco dos edifícios do complexo ferroviário e de seu entorno na referida cidade.

Palavras-chave: Conjunto arquitetônico férreo, Patrimônio cultural, Presidente Epitácio, Estrada de ferro, Degradação.
\end{abstract}

\section{THE IRON ARCHITECTURAL ENSEMBLE OF PRESIDENTE EPITÁCIO AS A LOCAL CULTURAL HERITAGE}

\begin{abstract}
The railways architectural complexes, as well as the railways in general, have great relevance to the location where it is inserted, being milestones in a process of development in many Brazilian cities. Through its facilities many cities reached political, economic and cultural development, thus being locally considered historical and cultural heritage. Therefore, this paper is structured in order to present a historical survey of the railway architectural ensemble of the city of Presidente Epitácio, as well as its due importance to the city and the state of conservation found nowdays. The methodologies of work is based on bibliographic and documentary research on the railroad history of the county of Presidente Epitácio - SP, as well as surveys in place of the buildings of the railway complex and its surroundings in that city.
\end{abstract}

Keywords: Railway architectural set, Cultural heritage, Presidente Epitácio, Railway, Degradation. 


\section{INTRODUÇÃO}

Um ícone de grande importância mundial para o transporte, que por anos foi sinônimo de avanço e crescimento foi o sistema de transporte ferroviário. De acordo com Borges (2011), a invenção do trem e a expansão das ferrovias pelo mundo representaram o próprio avanço do homem pela tecnologia.

A importância das construções férreas no mundo todo era visível. Possuir em seu território uma ferrovia na época era sinônimo de poder, assim como Kühl (1998, p. 58) cita que "as companhias ferroviárias tornaram-se, dessa forma, um dos maiores patronos da construção durante o século passado, e a arquitetura de suas estações e instalações conheceu toda a gama de estilos do século XIX."

Mas, a partir da década de 1990, devido ao processo de privatização das ferrovias em quase toda a América Latina, a preocupação com o patrimônio ferroviário aumentou, pois este encontra-se ameaçado de se perder totalmente o uso das estruturas e devido a necessidade de modernização dos sistemas. (ALLIS, 2006).

E assim, a então discussão desta pesquisa é dada sobre a antiga estação ferroviária de Presidente Epitácio, construída em 1922 às margens do Rio Paraná, que foi abandonada pela concessionária ALL no qual ficou com a linha-tronco da antiga Sorocabana em 1999. A situação que encontra-se hoje no local é de desuso e com seu conjunto arquitetônico abandonado e em degradação.

Após breve reflexão, o estudo apontado acima tem como objetivo geral trazer à tona a importância dessas estruturas como fundamentais para o desenvolvimento da cidade, sendo geradora de um patrimônio cultural que deve ser zelado para que não venham a ruir e se perder com o tempo e falta de uso.

\section{METODOLOGIA}

Neste estudo, optou-se pelo desenvolvimento do tema por meio de investigação bibliográfica e estudos no local. Quanto à pesquisa foram consultados livros e artigos diversos, com o intuito de produzir uma parte teórica embasada na literatura científica. No que toca aos estudos locais, foram escolhidos as instalações do conjunto arquitetônico férreo situados na cidade de Presidente Epitácio-SP, bem como seu entorno, sendo analisados com levantamentos fotográficos, métricos e seu estado de conservação.

\section{DISCUSSÃO}

A cidade de Presidente Epitácio, de acordo com Moroni (2011), está localizada no interior do estado de São Paulo, mais precisamente no Oeste Paulista, com divisa com o estado de Mato Grosso do Sul, no encontro com o Rio Paraná. No ano de 1922 chegou ao município um importante instrumento para a expansão da cidade: o transporte ferroviário através da estrada de Ferro Sorocabana, cujo destino final era em Presidente Epitácio, na barranca do rio Paraná, onde foi construído o Porto Fluvial.

Tal empreendimento teve uma grande ligação direta entre a história do município e o auge do seu crescimento tendo papel decisivo na vida da cidade que já tinha na ocasião 15 anos. A implantação dos trilhos férreos, lançados ainda sobre a terra bruta não serviria apenas como meio de transporte, mas, sobretudo, como um símbolo de poder, riqueza, progresso e referência cultural, chegando a circular por ali vagões para os mais diversos tipos de carga, tais como madeira, gado, cereais e passageiros, não deixando de contar com o vagão restaurante e o vagão leito. (EMUBRA, 2003).

Segundo Lanna (2002), as ferrovias em geral no Brasil foram responsáveis pela criação de vários territórios que ainda eram desconhecidos, e passaram a partir daí a serem gerados devido à passagem ou até mesmo a instalação de uma estação no local, fazendo necessário todo aparato 
de suporte para tal estrada de ferro e assim trazendo desenvolvimento e crescimento para determinada área. Esses aparatos são designados de complexo arquitetônico ferroviário, que no caso de Presidente Epitácio possui uma estação com um pequeno anexo, um armazém e um barracão aberto que servia como oficina. (FIGURA 01).

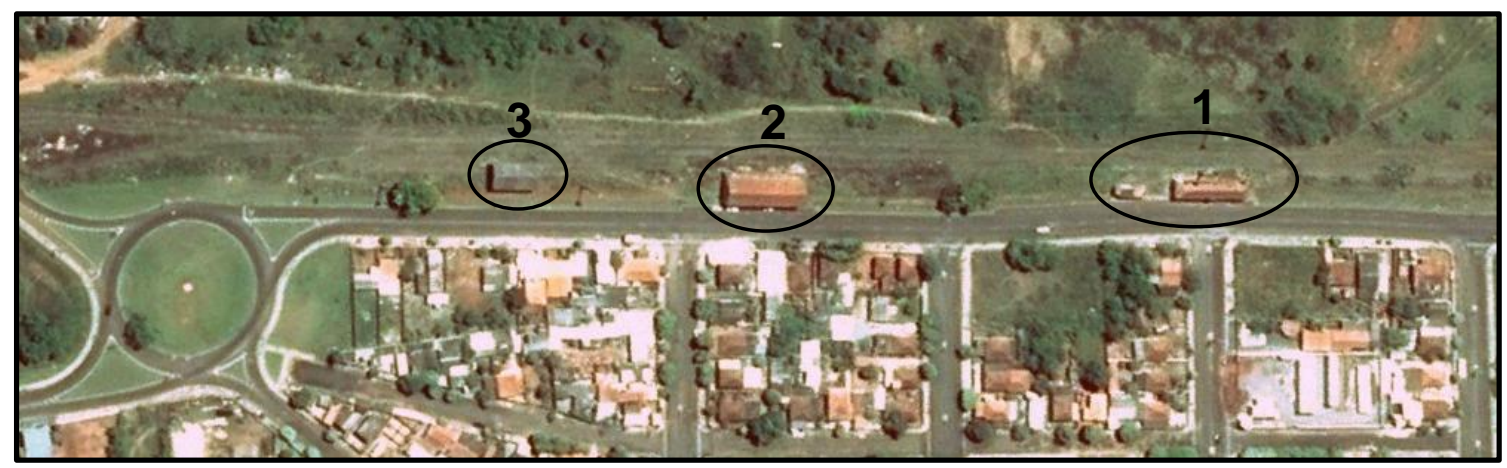

Figura 01. Conjunto arquitetônico férreo de Presidente Epitácio.

Fonte: Google Earth (2016), modificado: Autora (2016).

A edificação 1 corresponde a estação férrea propriamente dita, construída segundo Nunes (2009) no século XX e sua inauguração datada em 1 de maio de 1922 . O prédio da estação era a construção principal do conjunto ferroviário, era o local que acontecia o embarque e desembarque de passageiros junto a funções administrativas como por exemplo as retiradas de documentações de cargas, emissão e venda de passagens.

Tem-se ainda bem ao lado $(11,85 \mathrm{~m})$ um anexo, pequena edificação no qual possui 2 salas, banheiros e vestiário, servindo de apoio a edificação da estação (FIGURA 02).

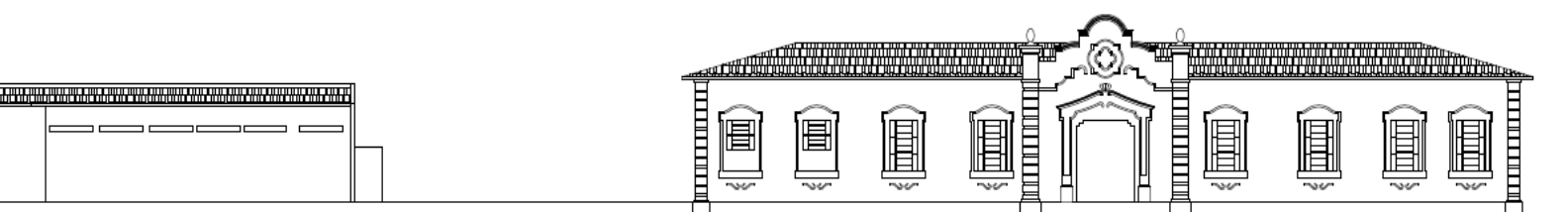

Figura 02. Estação Férrea e seu anexo.

Fonte: Prefeitura Municipal de Presidente Epitácio, modificado: Autora (2016).

Segundo Nunes (2009), a descrição física da estação se dá com uma fachada majestosa, com um estilo neocolonial, cravadas em sua parte alta as iniciais da Estrada de Ferro Sorocabana. Internamente é dividida por um hall de entrada, sete salas, banheiros e vestiários.

Esse estilo Neocolonial referido foi um estilo nascido segundo Kessel (1999) da reação contra o ecletismo dominante, encontrando como sua justificativa a ânsia de buscar, nas formas construtivas tradicionais do Brasil, uma arquitetura que pudesse ser definida como sendo natural de seu território.

Segundo Bruand (2010), como características de tal estilo tem-se o emprego de elementos retomados da arquitetura civil portuguesa dos séculos XVII e XVIII, sendo, por tanto, no caso das edificações encontradas em Presidente Epitácio uma arquitetura neocolonial da primeira fase, no qual foi construída na época entre 1914 a 1939, com elementos no qual remete a formas do passado, apresentando simetria, adornos, frontão e os demais edifícios do complexo compostos de estruturas mais simples.

Assim, partindo para a próxima edificação tem-se um pouco mais adiante a edificação 2 , que corresponde ao armazém da estação (FIGURA 03), local que era utilizado para armazenar as cargas que chegavam e também aquelas que iam ser despachadas. Sua construção é mais simples 
que o prédio da estação, era feita de tijolos aparentes e sua fachada não recebe adornos como na da estação. (NUNES, 2009).

E por fim, a edificação 3 é um barracão onde funcionava a oficina da antiga estação (FIGURA 04). Das três edificações presentes no conjunto essa era a mais simples, constituindo apenas por uma estrutura de ferro coberta por telhas de amianto.

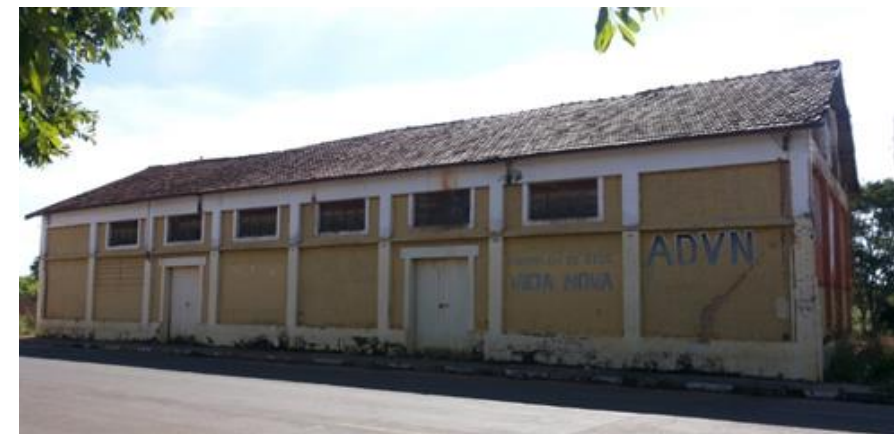

Figura 03.- Armazém da estação.

Fonte: Autora (2016).

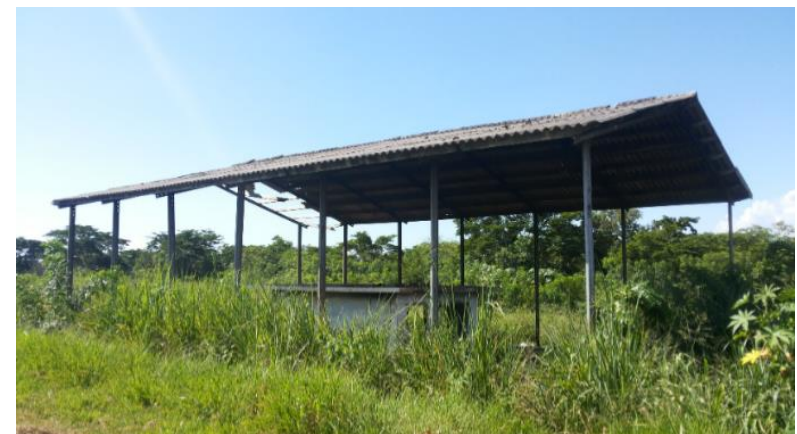

Figura 04 - Oficina da estação.

Fonte: Autora (2016).

Essas edificações são consideradas marcantes no local em que se inserem, principalmente a estação férrea (edificação 1) devido a sua arquitetura exuberante e diferenciada, típica da época em que foi construída (1922), sendo assim um marco do início das primeiras construções do município. Sua linha férrea, juntamente com o córrego que passa logo após, podem ser interpretados também como sendo limites da cidade, pois são esses elementos que fazem com que a cidade tenha uma divisão (FIGURA 05), podendo para alguns moradores locais até considerar a linha férrea como o "fim da cidade", mas na realidade existem mais bairros além disso, fazendo com que gere assim uma barreira física.

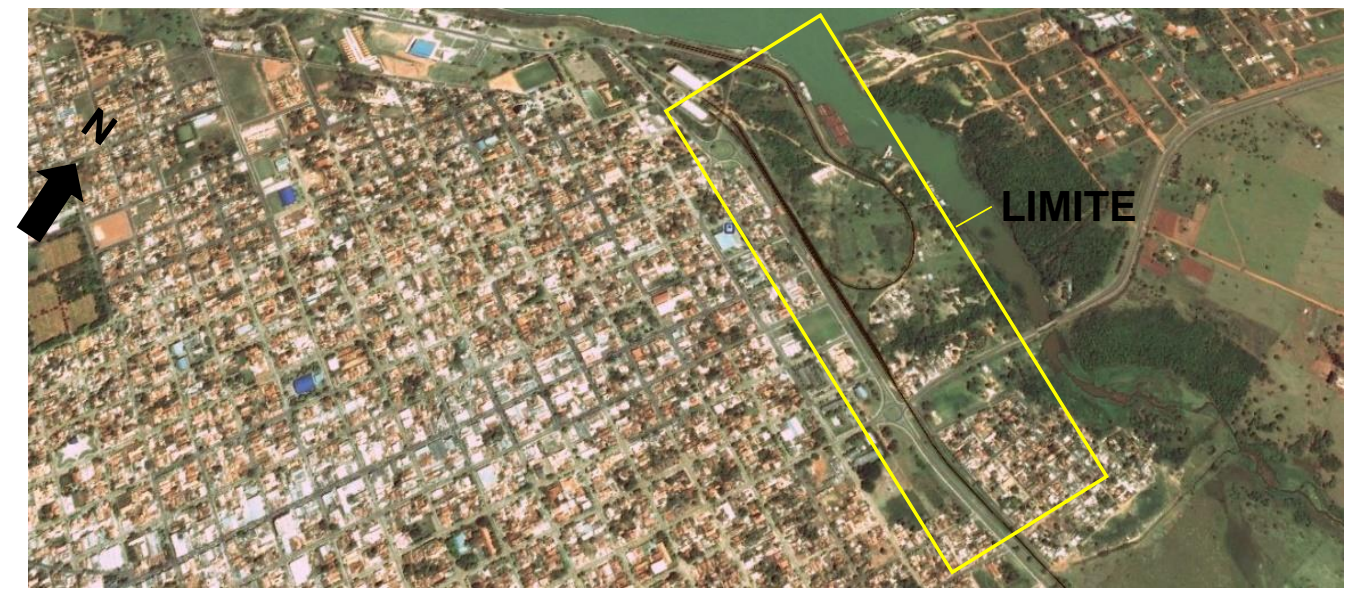

Figura 05. Linha limite da cidade.

Fonte: Google Earth (2016), modificado: Autora (2016).

Além das edificações do conjunto férreo, no período de instalação da linha férrea houve a venda dos lotes ao seu redor, para o chefe e os demais trabalhadores morarem por ali, configurando assim a vila da estação, ou também chamada vila da Fepasa.

Dentro desse contexto, no Brasil, segundo Finger (2009) foram inúmeros os casos de vilas operárias e ferroviárias construídas ao longo da primeira metade do século XIX e a segunda metade do século XX. No caso das ferroviárias, a prática de oferecer alojamento para os funcionários foi introduzida pelas Companhias Ferroviárias desde o momento de construção das 
primeiras linhas e, em alguns casos, foi mantida mesmo após terem sido encampadas pelo Governo Federal, como é o caso das residências dos ferroviários epitacianos que mesmo estando a estação sem funcionamento, toda a "Vila da Fepasa" como é chamada e suas casas típicas da época existem até os dias de hoje.

Essas construções das vilas ferroviárias e operárias cumpriu um papel de oferecer melhores condições de vida aos operários, além de afastá-lo dos antigos hábitos rurais que eram acostumados, de encurtar as distâncias de moradia-trabalho, sendo portanto a construção dessas vilas a melhor alternativa para garantir a permanência da mão-de-obra qualificada ligada ao empreendimento e próxima aos seus postos de trabalho. (FINGER, 2009).

Em toda a região de Presidente Epitácio, como a madeira era abundante, as construções dessas residências inicialmente eram feitas de madeira, só depois passando à construção de casas de alvenaria (FIGURA 06). (MORONI, 2011).
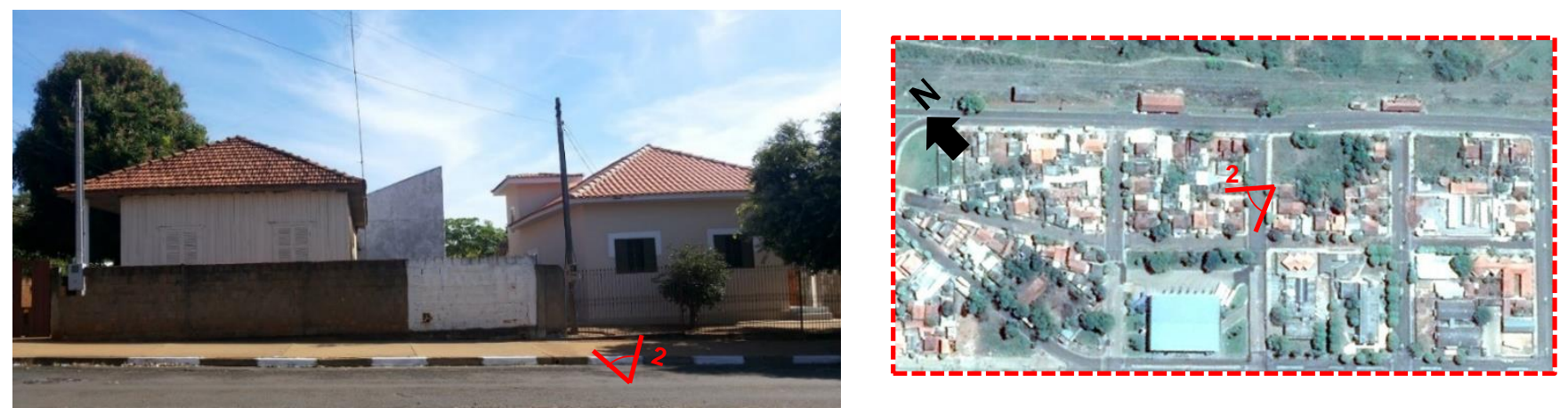

Figura 06. Casas de madeira da época da construção da ferrovia ao lado de uma casa de alvenaria nova.

Fonte: Google Earth (2016), modificado: Autora (2016).

Fonte: Autora (2016).

Segundo Moroni (2011), no ano de 1971, a então ferrovia passou a ser comandada pela empresa Fepasa (1971-1998) e após isso pela empresa privatizada ALL (1998-2002) e aos poucos foi entrando em decadência (passaram a circular apenas graneleiros e passageiros) e em 2002 esse elemento essencial para o surgimento e desenvolvimento da cidade, bem como para o Oeste Paulista em geral acaba por fim sendo paralisado.

Nestas mesmas circunstancias, Allis (2006) diz que as ferrovias do Brasil todo foram quase todas privatizadas, e trocadas pelo transporte rodoviário, passando assim a serem apenas campo da nostalgia. Contudo, as ferrovias no mundo todo ainda está presente nas milhares de estações, singelas ou majestosas, urbanas ou rurais, com seus bairros ferroviários, galpões, oficinas e toda a parte de aparato ferroviário que acaba hoje sendo encontrados em esquecimento e abandono.

E assim encontra-se hoje o conjunto arquitetônico férreo de Presidente Epitácio, em completo abandono, passando por degradações e vandalismo constantemente e já vindo a ruir (FIGURA 07 e 08). 


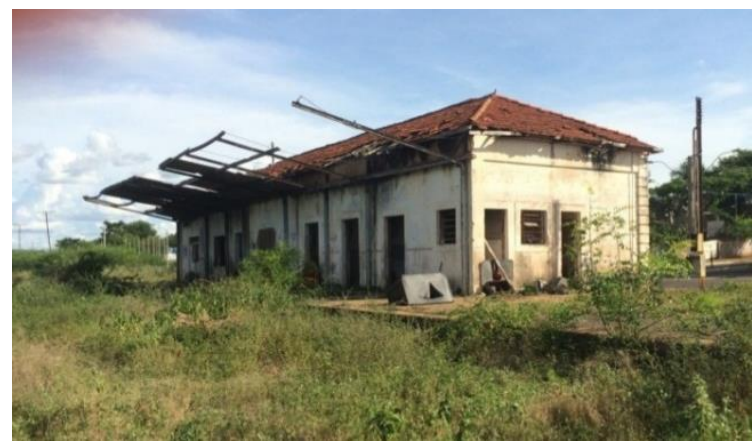

Figura 07. Estação Férrea em 2016. Fonte: Autora (2016).

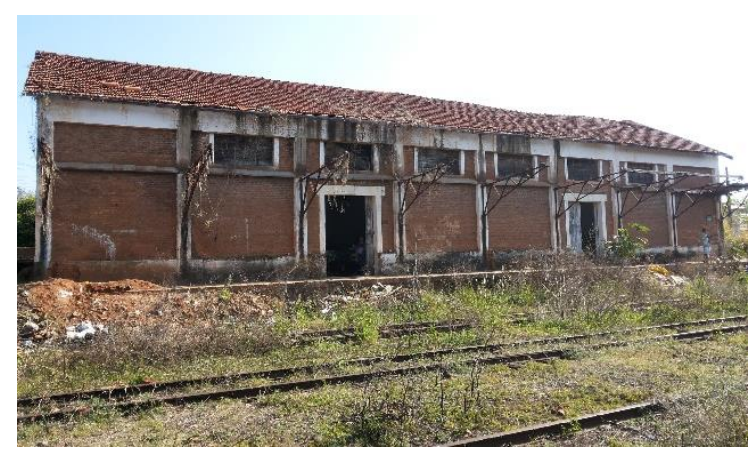

Figura 08. Armazém da estação em 2016. Fonte: Autora (2016).

\section{CONCLUSÃO}

Os conjuntos arquitetônicos férreos presentes nas inúmeras cidades brasileiras são consideradas peças fundamentais para os locais em que se inserem, consistindo em uma parte da história de inúmeros municípios, mantendo-se viva na memória de muitos daqueles que fizeram parte do funcionamento deste, sendo assim, considerados patrimônios culturais locais.

Esses patrimônios em geral hoje passam por sérios problemas de degradação e abandono, merecendo uma atenção especial para que não venham a se perder com o tempo, pois ignorar este patrimônio é ignorar a história da cidade, ou melhor dizendo, a história de uma população, que esteve intimamente ligadas a estrada de ferro.

Por tanto, essas construções dependem muito de uma conservação para a proteção desses bens, no caso do conjunto existente em Presidente Epitácio uma urgente revitalização desses espaços, a fim de garantir sua existência num futuro próximo.

\section{REFERÊNCIAS}

ALLIS, T. Turismo, patrimônio cultural e transporte ferroviário: Um estudo sobre ferrovias turísticas no Brasil e na Argentina. Dissertação (Mestrado em Integração da América Latina) - USP, 2006, São Paulo. Disponível em: www.teses.usp.br/teses/disponiveis/84/.../Dissertacao_Thiago_Allis.pdf >. Acesso em: 10 fev. 2016.

BORGES, B. G. Ferrovia e Modernidade. Dossiê Ferrovias, Revista UFG, Goiânia, Ano XIII no 11, dez. 2011.

em: <http://www.proec.ufg.br/revista_ufg/dezembro2011/arquivos_pdf/dossie_ferrovia.pdf>. Acesso em: 15 fev. 2016.

BRUAND, Y. Arquitetura Contemporânea no Brasil. Editora: Perspectiva. São Paulo, 2010.

EMUBRA. $\quad$ Presidente $2003 . \quad$ Epitácio. $\quad$ Disponível $:<$ http://camarapprudente.sp.gov.br/historia/hist_oeste/cidades/pepitacio/transportes.html>. Acesso em: 1 mai. 2016.

FINGER, A. E. Vilas Ferroviárias no Brasil: Os casos de Paranapiacaba em São Paulo e da Vila Belga no Rio Grande do Sul. Dissertação (Mestrado). UNB - Universidade de Brasília. Nov. 2009. Disponível em:< http://repositorio.unb.br/handle/10482/5282?mode=full>. Acesso em: 7 mai. 2016.

KESSEL, C. Estilo, Discurso, Poder: Arquitetura Neocolonial no Brasil. História Social. N. 6. Campinas - $\quad$ SP, $1999 . \quad$ Disponível em:< 
http://www.ifch.unicamp.br/ojs/index.php/rhs/article/viewFile/179/170>. Acesso em: 14 mai. 2016.

KÜHL, B. M. Arquitetura do ferro e arquitetura ferroviária em São Paulo: Reflexões sobre a sua preservação. São Paulo: Ateliê editorial: FAPESP: Secretaria da Cultura, 1998.

LANNA, A. L. D. Cidades e ferrovias no Brasil do século XIX: algumas reflexões sobre a diversidade dos significados sociais e impactos urbanos - Jundiaí e Campinas. In: SEMINÁRIO DE HISTÓRIA DA CIDADE E DO URBANISMO, 2002, Salvador. Disponível em: < http://unuhospedagem.com.br/revista/rbeur/index.php/shcu/article/view/883>. Acesso em: 15 fev. 2016.

MORONI, B. G. Presidente Epitácio: 100 anos da Fundação da Cidade. Do Autor, 2011. Disponível em:

<http://www.presidenteepitacio.com.br/epitacio/Livros\%20Godoy/100\%20ANOS\%20DE\%20EPITA CIO\%20ebook_2012.pdf>. Acesso em: 15 fev. 2016.

NUNES, A.B. Inventário do Patrimônio industrial: a estação ferroviária da cidade de Presidente Epitácio. UNESP: Rosana - São Paulo, 2009. Disponível em: <http://ad.rosana.unesp.br/docview/directories/Arquivos/DTA/Biblioteca/2009\%20\%2012/2009b/Andr\%C3\%A9a\%20Batista\%20Nunes.pdf>. Acesso em: 12 março 2016. 